\title{
Time scales of shallow magma chamber replenishment at Campi Flegrei caldera.
}

\author{
Chiara P. Montagna ${ }^{1, *}$ and Paolo Papale ${ }^{1}$ \\ ${ }^{1}$ Istituto Nazionale di Geofisica e Vulcanologia, sezione di Pisa, \\ Italy \\ *chiara.montagna@ingv.it
}

June 5, 2018

\begin{abstract}
Ascent of primitive magmas from depth into shallow, partially degassed reservoirs is commonly assumed to be a viable eruption trigger. The resulting processes of convection and mixing have played an important role both in pre- and syn-eruptive stages in many eruptions of different sizes at the unrest Campi Flegrei caldera in Southern Italy.

We performed numerical simulations of magma chamber replenishment referring to an archetypal case whereby a shallow, small magma chamber containing degassed phonolite is invaded by volatile-rich shoshonitic magma coming from a deeper, larger reservoir. The system evolution is driven by buoyancy, as the magma entering the shallower chamber is less dense than the degassed, resident phonolite.

The evolution in space and time of physical quantities such as pressure, gas content and density is highly heterogeneous; nonetheless, an overall decreasing exponential trend in time can be observed and characterizes the efficiency of the whole process. The same exponentially decreasing trend can be observed in the amplitude of the synthetic ground deformation signals (seismicity over the whole frequency spectrum) calculated from the results of the magmatic dynamics. Depending on the initial and boundary conditions explored, such as chamber geometry or density contrast, the time constant thus the inferred duration of the process can vary. An initial vigorous phase of convection and mixing among the two magma types reaches an asymptotic stage after a few hours to half a day.
\end{abstract}


Independently, the evolution of pressure in the magmatic system also depends on the initial and boundary conditions, leading either to eruptionfavorable conditions or not. Relating the time scales for convective processes to be effective with their outcomes in terms of stresses at the boundaries of the magmatic system can substantially improve our ability to forecast the evolution of volcanic unrest crises worldwide.

Keywords: magma chamber, magma mixing, caldera unrest, Campi Flegrei, magma dynamics

\section{Introduction}

The restless Campi Flegrei caldera, in southern Italy, is one of the highest-risk volcanic areas in the world, due to the millions of people living in its surroundings, that include the city of Naples. Within a radius of around $7 \mathrm{~km}$ intracalderic craters and volcanic edifices testify the post-collapse eruptive history of the volcano, that last erupted in 1538 AD (Di Vito et aL, ए999; D'Oriano et aL, 2010.5; Di Vito et al, 2016). Nowadays, the system is characterized by intense hydrothermal circulation with abundant fumaroles, episodes of accelerating ground deformation, and sporadic seismic swarms (Chiodini et al, 2015).

Geochemical (Arienzo et al, 20019; Di Renzo et al, 2010) and geophysical (Wudenherc and Zollo, 2004; Zollo et al, 2008; De Siena et al, L2010) evidence suggests that the plumbing system at Campi Flegrei is composed of a large, deep (around $8 \mathrm{~km}$ ), dominantly shoshonitic reservoir (Mangiacapra et al., 20008), and shallower, smaller (less than $1 \mathrm{~km}^{3}$ ) reservoirs that discontinuously occur in a depth range of $3 \mathrm{~km}$ to $6 \mathrm{~km}$ and host small pockets of trachytic to phonolitic magmas (Arienzo et al, 2010).

The arrival of primitive, volatile-rich magma from depth into the shallow reservoirs has been identified as a viable trigger mechanism for some past eruptions at Campi Flegrei (Tonarini et al, [2009). Numerical simulations of this process highlight the convective patterns leading to efficient mingling between the two magmas (Montagna et al., 2015). The resulting pressure oscillations generate ground displacement patterns in the ultra-long-period band (ULP, $10^{-4} \mathrm{~Hz}$ to $10^{-2} \mathrm{~Hz}$ ), that can be recorded by strainmeters networks (Longo et al., 2012b; Bagagli et al., 2017).

In this work we perform a through analysis of the time scales over which the aforementioned replenishment processes are expected to be efficient. Those 
same processes can be related to the stress evolution at the reservoir boundaries in order to determine in which cases the conditions for eruption are met. The method can provide estimates of mixing-to-eruption time scales, which can be of great help for hazard assessment.

\section{Material and Methods}

\section{$2.1 \quad$ Numerical model}

Numerical simulations of magma chamber replenishment at Campi Flegrei were performed using the finite-element $\mathrm{C}++$ GALES code (Longo et al., 2012a). The physico-mathematical model describes the time-dependent $2 \mathrm{D}$ dynamics of a compressible-to-incompressible multicomponent mixture consisting of liquid (or crystal suspension) in thermodynamic equilibrium with an $\mathrm{H}_{2} \mathrm{O}+\mathrm{CO}_{2}$ gas phase at the local conditions of pressure, temperature and composition. The numerical algorithm used in the solution of the conservation equations is based on an extension of the finite element formulation by Hauke and Hughes (19.98) to include multicomponent fluids (Longo et al., 20106), allowing the investigation of processes involving mixing of fluids, chemical changes, and phase transitions. The algorithm consists of a space-time discretization with Galerkin least-squares and discontinuity capturing terms, with third order accuracy in time and space. This method allows the simulation of both compressible and incompressible flow dynamics (Shakib et al, 1991; Chalot and Hughes, 1994; Hauke and Hughes, 1998; Garg et a1., 2018), and it is effective in stabilizing the numerical solution without introducing excessive numerical diffusion. A large number of problems can be solved, such as natural and forced convection, shock waves and their interaction with contact discontinuities, evolution of internal interfaces in incompressible or compressible flows, and bubbly flows with evaporation or gas dissolution. The conservation equations for the mass of single components and momentum of the whole mixture, together with the gas-liquid thermodynamic equilibrium model and the constitutive equations for mixture properties (density and viscosity), are discretized and solved for the primitive variables pressure, velocity, temperature, and concentration of components. Magmas are described as ideal mixtures with components that may be either in the liquid or gaseous state, with instantaneous phase change according to the non-ideal multicomponent $\mathrm{H}_{2} \mathrm{O}+\mathrm{CO}_{2}$ saturation model of Papale et al. (2006). The solid phase (suspended crystals) can be taken into account in the computation of mixture 
properties. Gas bubbles are assumed to be undeformable, a good approximation if the bubble size is smaller than $\sim 10 \mu \mathrm{m}$ (Marchetti et al, 2004). This corresponds to a gas volume of $5 \%$ to $50 \%$ for bubble number densities in the range $1 \times 10^{14} \mathrm{~m}^{-3}$ to $1 \times 10^{15} \mathrm{~m}^{-3}$. The role on the relevant properties (density and viscosity) of dissolved water and of dispersed gas and solid phases, and the mutual roles of $\mathrm{H}_{2} \mathrm{O}$ and $\mathrm{CO}_{2}$ in affecting their saturation contents, are accounted for. Mixture density is calculated using the Lange (II994) equation of state for the liquid phase, real gas properties and standard mixture laws for multiphase fluids. Mixture viscosity (under the assumption of Newtonian rheology) is computed through standard rules of mixing (Reid et al., 1977) for one phase mixtures and with a semi-empirical relation (Lshii and /uber, 1.979) in order to account for the effect of non-deformable gas bubbles. Liquid viscosity is modeled as in Giordano et al. (2008), and it depends on liquid composition and dissolved water content.

\subsection{Campi Flegrei system setup}

In order to understand the dynamics of magmas beneath the Campi Flegrei caldera, we simplify the magmatic system trying to retain its most peculiar features. A schematic picture of the feeding system includes the deep magmatic sill containing the less evolved, $\mathrm{CO}_{2}$-rich shoshonitic magma; and more or less persistent features, such as dikes, fractures or conduits, linking the deep reservoir to shallower, degassed batches of magma. Shallower reservoirs contain magmas with compositions from trachyte to phonolite.

We model the injection of $\mathrm{CO}_{2}$-rich, shoshonitic magma coming from a deep reservoir into a shallower, much smaller chamber, containing more evolved and partially degassed phonolitic magma. The deep reservoir is schematized as a sill; the geometry of the shallow chamber has been varied from oblate to prolate in a set of simulations, as shown in Figure $\mathbb{~}$. Initial conditions for the simulated cases are reported in Table $\mathbf{m}$.

The top of the deep reservoir is at $8 \mathrm{~km}$ depth, and its horizontal and vertical semi-axes measure $4 \mathrm{~km}$ and $0.5 \mathrm{~km}$, respectively. The shallow reservoir has its top at $3 \mathrm{~km}$ below the surface; its surface area is kept to $0.25 \times 10^{6} \mathrm{~m}^{3}$, representing a volume of magma of order a few tenths of $\mathrm{km}^{3}$. The connecting dike is $20 \mathrm{~m}$ wide. The oxides composition of the two magmas is detailed in Table 2 .

At the initial time, the two magmas are placed in contact at the bottom of 

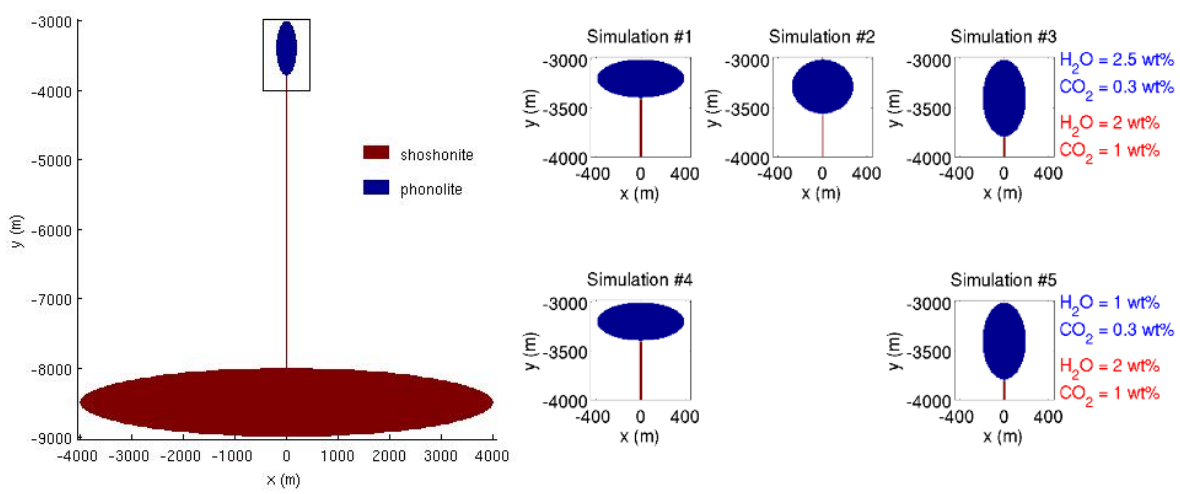

Figure 1: Summary of the five simulated settings. The geometry and volatile content of the shallow reservoir have been varied in a range of conditions relevant to Campi Flegrei.

the shallow chamber (top of the feeding dike: Figure $\mathbb{D}$ ). Because of the higher volatile content thus lower overall density of the deeper magma, the system is gravitationally unstable. Therefore, the deep magma tends to rise into the shallow chamber, pushing the resident magma down through the feeding dike.

We conceived different setups in order to explore a parameters' range suitable for the Campi Flegrei feeding system. Keeping the upper chamber top at a depth of $3 \mathrm{~km}$ and its $2 \mathrm{D}$ cross-sectional area, we changed its geometry from a sill to a circle and to a vertically elongated, dike-like ellipsoid. For the two ellipsoidal chambers, we also varied the volatile content of the shallow phonolitic

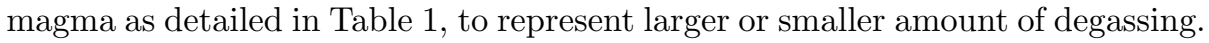
The deep shoshonitic magma contains in all cases $2 \mathrm{wt} \% \mathrm{H}_{2} \mathrm{O}$ and $1 \mathrm{wt} \% \mathrm{CO}_{2}$ (Table $\mathrm{⿴囗十)}$ ). These quantities represent the total volatiles' amount, which is distributed between liquid and gas phases according to the local conditions and the saturation model of Papale et al. (2006). The simulated systems are closed, with fixed boundaries. The effect of wall-rock elasticity on the chamber dynamics is neglected, as it is assumed to cause small pressure changes with respect to those originating from the magma dynamics (see also section $\mathbf{a}$ ).

The setup, albeit being a simplification, aims at representing complex, interconnected reservoirs that are believed to exist at many active volcanoes, including Campi Flegrei (Amoruso et al, 2014); its basic features are chosen as to avoid arbitrariness whenever possible. 


\subsection{Shallow reservoir dynamics}

This work focuses on the evolution of the shallow chamber as a consequence of the replenishment process (Montagna et al., 2015; Papale et al., 2017), which has been testified in a variety of settings, in both volcanic and plutonic environments (Perugini and Poli, 2012). The onset and development of convection and mixing following the arrival of magma from depth into a shallower reservoir have been found to depend on system geometry (Turner and Campbell, 1986) as well as on the physical properties of the magmas involved, notably density and viscosity (Bachmann and Bergantz, 2006).

Significant physical quantities including pressure, density and gas fraction can be described using a lumped approach (Degruyter and Huber, 20144; Papale et al, 2017), whereby the spatial heterogeneities are averaged out in order to obtain a larger-scale description of the reservoir dynamics. The lumped value of the variable $y$ in the region $\mathcal{D}$ is given by

$$
y_{\mathrm{L}}=\int_{\mathcal{D}} y(\mathbf{x}) d \mathbf{x} .
$$

Figure 『 shows the heterogeneous space-time evolution resulting from the simulations alongside the corresponding lumped time series, obtained by numerical integration of the simulation results in space.

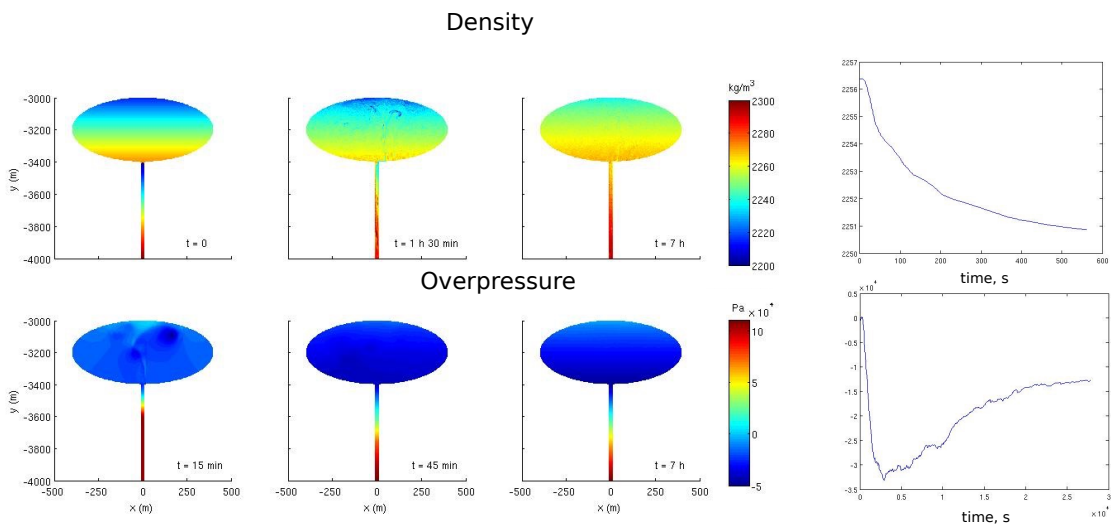

Figure 2: Space-time evolution of density and overpressure in the shallow reservoir for simulation 1 , and corresponding lumped time series.

The upper reservoir is an open system, exchanging mass with the surroundings through the feeder dike. A measure of the mass exchange between the two 
magmas in a certain region of the domain is given by the convection efficiency $\eta_{\mathrm{C}}:$

$$
\eta_{\mathrm{C}}=\frac{\left|m_{\mathrm{P}}(t)-m_{\mathrm{P}}(0)\right|}{m_{\mathrm{P}}(0)} .
$$

$\eta_{\mathrm{C}}$ represents the relative variation of the mass of the phonolitic magma $m_{\mathrm{P}}$ with time $t$ (Montagna et al., 2015); it is a lumped variable by definition.

The efficiency of mass exchange depends on the dike width as well, because larger dikes will allow for easier flow and enhanced mass exchange. A dike width of $20 \mathrm{~m}$ has been chosen for consistency with exposed mafic dikes and to avoid too rapid cooling near the walls (Costa and Macedonio, 20102).

\section{Results}

\subsection{Magma Dynamics}

In all the simulated scenarios, plumes of more primitive magma rise into the shallow chamber and originate convective patterns enhancing magma mixing, while a portion of the degassed phonolitic magma initially hosted in the chamber sinks into the feeder dike (Figure B).

Soon after the start of the simulation, disruption of the initial interface by buoyancy forces produces a series of discrete plumes of light magma rising through the shallow chamber and reaching its top after having developed complex velocity fields. At the same time, part of the dense magma originally hosted in the shallow chamber sinks into the feeding dike. Intense mixing originates at the dike level, so that no pure shoshonitic end-member can be found in the shallow chamber; the rising plumes are rather made of a mixture with $30 \mathrm{wt} \%$ to $50 \mathrm{wt} \%$ deep component. In our framework, only mechanical mixing is considered, as chemical reactions apart from volatile exsolution/dissolution are not implemented in the numerical scheme. Therefore, mixing at the scale of the simulation, with maximum resolution of order $1 \mathrm{~m}$, refers to mechanical mingling rather than chemical mixing. The simulated dynamics suggests a complex pattern of convection and mixing (or mingling) whereby the original dense magma rapidly mixes up with the volatile-rich, lighter magma coming from depth at chamber bottom or dike level. The original phonolite carried down into the dike mixes up with the shoshonite; the mixed magma is overall lighter than the magma above it or in its immediate surroundings, therefore part of the initially 

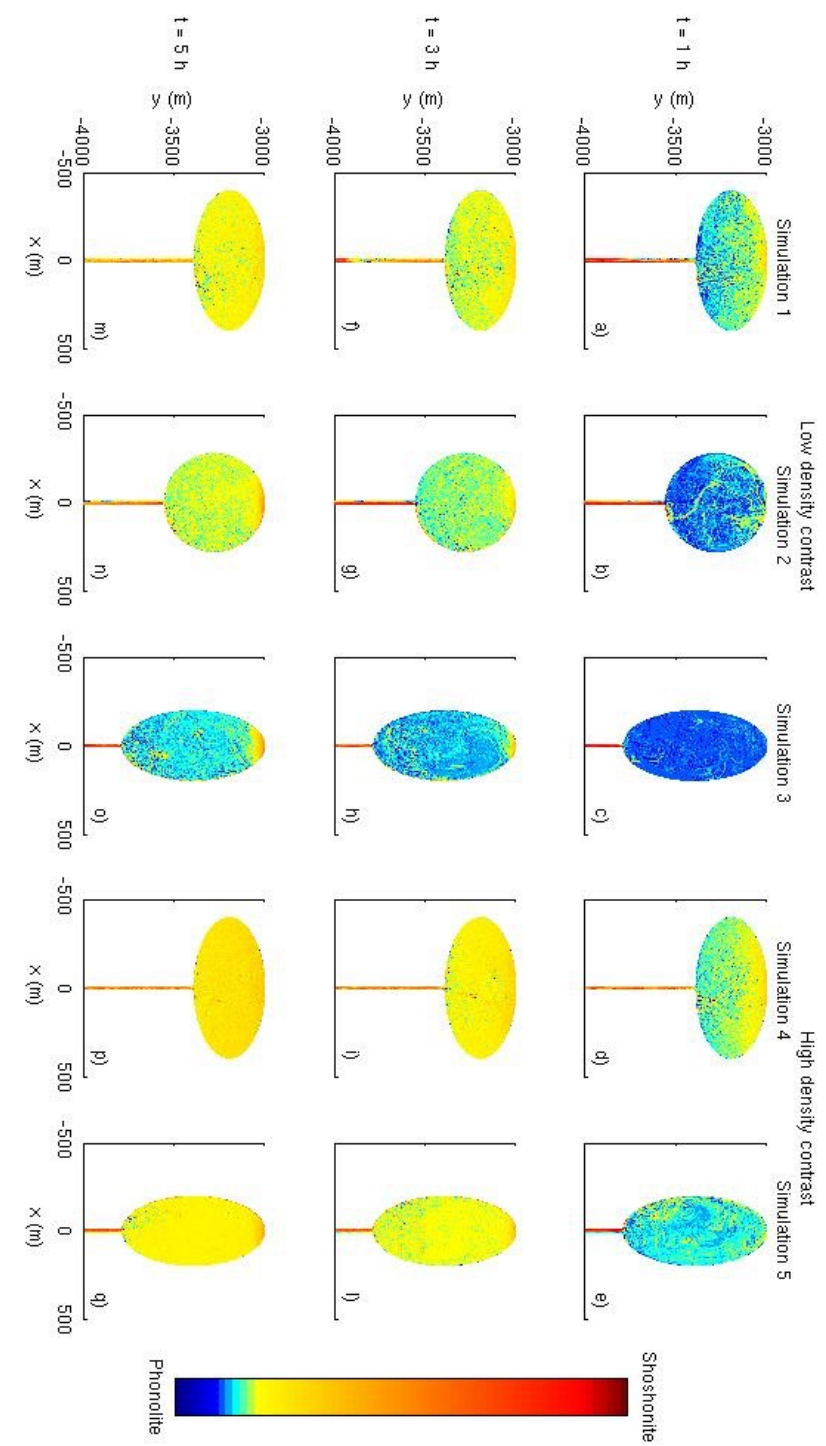

Figure 3: Space-time evolution of composition in the upper region of the simulated domain, for the different scenarios. Rows represent different times, columns represent different simulations.

sunk magma is carried up again into the shallow chamber, while other portions continue to sink down into the dike. This complex process originates a compositional, density, and gas volume stratification inside the chamber (Figure 『). The 


\subsection{Exponential Trends and Time Scales}

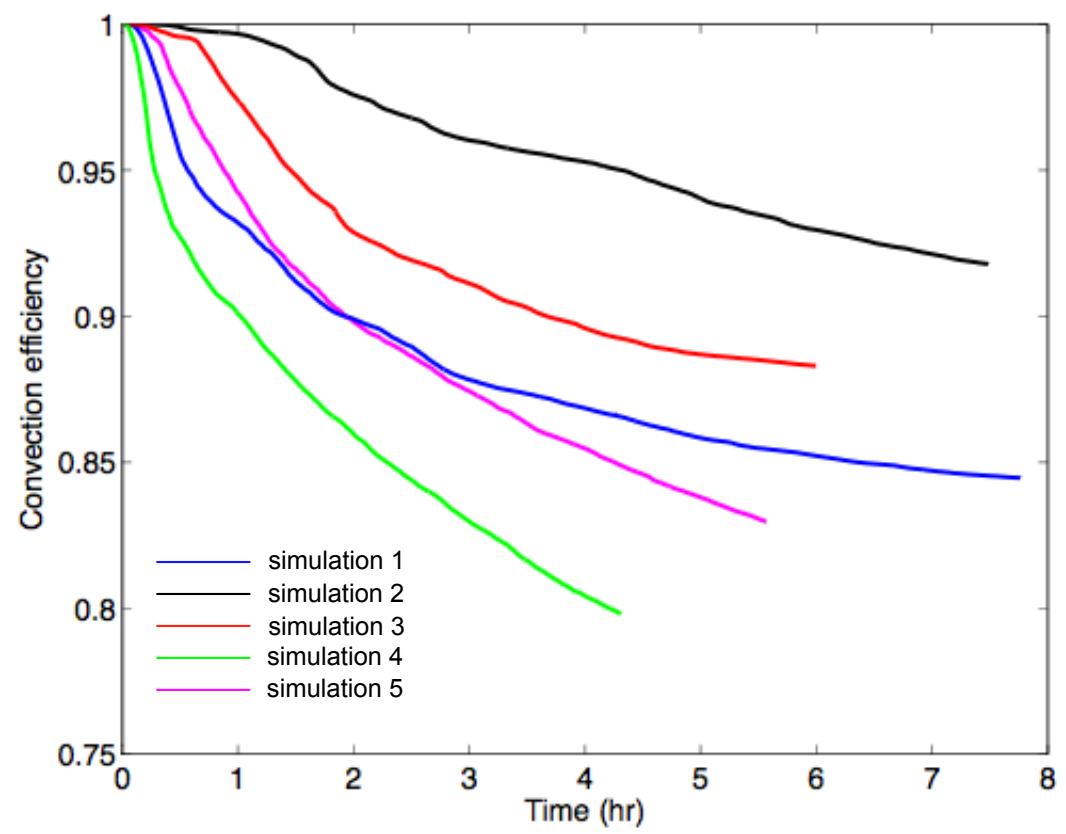

Figure 4: Time evolution of convection efficiency $\eta_{C}(t)$ for the different simulated scenarios.

original density contrast at chamber bottom is smoothed, so that the convective process tends to slow down in time.

Figure 团 shows the time evolution of the convection efficiency for all the simulations in Table $\mathbf{m}$. Convection and mixing slow down with time, as revealed by the progressive decrease of the slopes. An initial vigorous phase leads to an asymptotically decreasing efficiency of the mingling process. The density contrast among the entering and the resident magmatic mixtures becomes smaller as the dynamics proceeds and mixing becomes intense both in the chamber and in the feeding dike. More than $80 \%$ of the dense, degassed magma initially residing in the shallow chamber remains at chamber level after waning of the convective process. The complex patterns of convection and mixing are such that most of the degassed magma is not carried down to larger depths when an asymptotic stage has been reached. While shallow chamber degassing creates 
unstable conditions by increasing the density of the magma at shallow levels, the ingression of small amounts of volatile-rich magma rapidly re-establishes a quasi-equilibrium dynamical condition, whereby small batches of mixed magma still enter the chamber while other batches sink into the dike (Figure [1).

Mixing efficiency in magmas has been hypothesized to follow and exponentially decrasing trend in time, when measured through the degree of homogeneization (Section 3.2.1; Morgavi et al. (2013)). The asimptotically decreasing trend of convection efficiency in Figure $⿴$ can be fitted well by an exponentially decaying function in time, given by

$$
\eta_{\mathrm{C}}=\eta_{0} \exp (-t / \tau)+\eta_{1}
$$

The time evolution of the lumped quantities density and gas volume is also found to follow exponential trends for all the simulated scenarios, given by

$$
\begin{aligned}
\rho & =\rho_{0} \exp (-t / \tau)+\rho_{1}, \\
\phi & =\phi_{0}[1-\exp (-t / \tau)] .
\end{aligned}
$$

In Equations (际) and (田) above, $t$ is time and $\tau$ is the time constant; $\rho$ and $\phi$ are density and gas volume fractions, respectively, and subscripts 0 and 1 indicate constants. Figure 5 shows the best exponential fits for simulation 1; Table $\mathbf{3}$ lists the time constants obtained by fitting the data from the different simulations. The goodness of fit, measured by the coefficient of determination $R^{2}$, is very good, as all fits have $R^{2}>0.99$. Every setup is characterized by a a single time constant, that is obtained from separately fitting all the relevant quantities (Figure [)

The decay times obtained by the exponential fits range from 2 hours to 13 hours. Sill-like reservoirs, as compared to more vertically elongated, dike-like geometries, reach the asymptotic state first, thus are characterized by shorter time constants; the density contrast plays a less relevant role in determining the replenishment time scale (Appendix A). 


\subsubsection{Concentration variance decay}

The degree of homogenization of fluid mixtures can be measured by the singlecomponent concentration variance $\sigma$ (Lim and Haller, 20104), defined by

$$
\sigma^{2}(t)=\frac{\sum_{j=1}^{N}\left(C_{j}(t)-\mu\right)^{2}}{N} .
$$

In the above, $C_{j}(t)$ is the time-varying concentration of the component considered, $\mu$ its mean concentration and $N$ is the number of samples. As the system approaches homogeneity with mixing, this quantity decreases towards zero. Laboratory experiments of magma mixing have shown an exponential decrease of concentration variance in time (Morgavi et al., 2013). We evaluated concentration variance and its time evolution for the 5 different simulation setups by choosing a number of sample points $N=155$ within the upper chamber. We performed calculations for the composition of the shoshonitic end-member $X_{\mathrm{S}}$, as the composition of the phonolitic magma is defined as $X_{\mathrm{P}}=1-X_{\mathrm{S}}$. The mean composition is thus $\mu_{\mathrm{S}}=0.875$, the average composition over the whole domain (Figure $\mathbf{D}$ ). Figure $\mathbf{6}$ shows the results of concentration variance decay calculations, alongside the fits to exponentially decaying functions. Concentration variance decays exponentially in our numerical experiments; the decay times are the same observed for the physical quantities described in Section $\mathbf{3 . 2}$ - mixing efficiency, density and gas volume fraction.

\subsection{Ground Deformation}

The stress variations at the boundaries of the fluid system due to magmatic convection and mixing can be calculated from the results of the numerical simulations. These perturbations to the original stress state of the crust are propagated to the Earth's surface, and can be recorded as ground deformation. To evaluate the observable effects in terms of ground deformation due to the simulated magmatic dynamics, as a first approximation we considered the crust as an homogeneous, infinite medium, and calculated seismic wave propagation by Green's functions integration.

Wave propagation is calculated by assuming continuity of pressure and stress at the magma-rock interface. One-way coupling between fluid and confining rock has proved a necessary approximation in order to limit computational needs; full coupling could bring about resonance effects (e.g., Chonet, 1986) that are expected to be less energetic than the modes related to the dynamics. The 
assumption of homogeneous and infinite rock medium is expected not to play

a major role as the most energy associated to magma convection and mixing is in the frequency band $10^{-4}-10^{-3} \mathrm{~Hz}$ (Longo et al., 2012b; Bagagli et al., 2017), corresponding to wavelengths of thousands of $\mathrm{km}$. We are thus dealing with quasi-static ground deformation that is not severely affected by medium heterogeneities and finiteness.

Figure $\square$ shows the amplitude of the synthetic seismic signal relative to simulation 1 at a station right above the top of the magmatic system, from which the continuous component has been removed. The amplitude shows a decreasing trend in time, that can be related to the waning magmatic dynamics underground. The seismic amplitude decreases following very closely the convection efficiency trend, thus with the same exponential behaviour described in Section B.2.

This well-defined decay in seismic energy in the ULP frequency band can be detected from ground deformation measurements obtained by tiltmeters and strainmeters, providing a means to discriminate waning magma dynamics underground and contributing to hazard assessment.

\section{Discussion}

Analysis of the dynamics of shallow magma chamber replenishment at Campi Flegrei caldera shows that convection and mixing processes within magmatic systems can be described by exponentially decreasing trends in time. An initial vigorous phase of mass exchange among the incoming and the resident magmas is followed by slowing interactions that asymptotically tend to the homogenization of the system. The initial density contrast, which is the driving force behind the overall dynamics, diminishes with increasing mixing time, causing the observed behaviour.

The mathematical formulation of Equations (지) and (四) allows to define precise time scales over which magma chamber replenishment processes are expected to be effective. Every simulated setup is thus characterized by a welldefined and consistent time scale over which convective mingling processes are effective. At Campi Flegrei, shallow chamber replenishment as depicted above is thus characterized by typical mixing time scales in the range of some hours. Following a similar approach, analysis of concentration variance decay in experiments of magma mingling yields mingling-to-eruption time scales in the range 
of tens of minutes (Perugini et al., 2015). Our results are in broad agreement because explosive eruptions as those used as basis for the experimental setup are expected to correspond to large ascent rates and more efficient mixing dynamics.

Eruptions can be triggered by chamber replenishment if the process is accompanied by a pressure increase in the magmatic system, that can cause rupture of the host rock and initiate magma ascent towards the surface. The space-time evolution of pressure in the case of buoyancy-driven replenishment analyzed here is highly heterogeneous (Papale et al., 2017) and strongly depends on the initial conditions of the system as shown in Figure $\mathbf{8}$, that reports lumped pressure variations obtained from the model in the shallow reservoir. A pressure increase is favoured by smaller density contrasts and less efficient dynamics; these cases are also characterized by longer mixing time scales (Table B). Albeit pressure variations at the fluid boundary in the conditions explored in this work are rather small, on the order of $10^{-1} \mathrm{MPa}$, they might be sufficient to initiate a small-scale eruption in the fractured, low-tensile-strength shallow rock system of Campi Flegrei (Krumbholz et al., 2014; Giudicepietro et al., 2017).

The results described above have necessarily been obtained under some assumptions, mostly because of the large computational costs associated to the detailed description of magmatic mixtures and their dynamical interactions detailed in Section [2.].

Extension to fully three-dimensional systems is expected not to change drastically the time scales over which convection is efficient, given that the dynamical interactions among the two magmas are mostly concentrated far from the boundaries (Bain et al., 2013). Assumed rigidity of the fluid boundary has implications on the space-time evolution of pressure within the domain. A visco-elastic response of the walls would have a buffering effect on the pressure variations, thus on volatiles' exsolution in the chamber. Given the small pressure variations in the magmatic system as a consequence of replenishment, though, that are in the range of $0.1 \mathrm{~Pa}$ (Figure $\nabla)$, the effect on chamber volume is expected to be negligible. The assumptions of isothermal, crystal-free magmas stem from the specific setting of Campi Flegrei: magmatic compositions are relatively mafic and not too different among the two end-members (Table 『). Products with the compositions used in our modeling have been found to have very little phenocrysts, and the temperature differences inferred are negligible (Mangiacapra et al, 2(108). Solving the dynamics for an isothermal system, on the other hand, greatly reduces computational needs as the energy conservation equation does not need to be solved. The effect of wall cooling can be neglected on 
the very short time scales analyzed here. Our model is thus meaningful for melt-dominated, crystal-poor magma reservoirs, which is expected to be the case for Campi Flegrei (Di Renzo et al., 2011). Long-lived magma chambers can slowly solidify and originate mush zones, that, on the contrary, are dominated by crystals (Pistone et al, , 2017). Convection and mixing are common in mushy reservoirs, too (Schleicher et al., 2016), but their features can depart significantly from our results (Parmigiani et al., 2014).

Notwithstanding the enormous progress made towards reliable eruption forecasting, that is nowadays sometimes successful (Sparks, 2010:3), there is still no widely accepted means of discriminating the precursor of an impending eruption, especially at long-dormant volcanoes (Druitt et al, 2012). Our results offer insights on the time scales of mixing among different magma types, that has been invoked as eruption trigger at many volcanoes worldwide (e.g., Wark et al., 2007; Druitt et all, 2012). Application to Campi Flegrei, one of the highest-risk volcanic areas in the world, yields relatively short time scales from magma arrival from depth to waning of shallow dynamics, which not necessarily leads to eruption. As ground deformation signals related to magmatic convection can be identified in strainmeter records (Bagagli et al., 2017), their duration and amplitude modulation in time can be used for improved hazard assessment, possibly discriminating between unrest phases leading or not to eruptive activity.

\section{Appendix A: Convective Overturn in Boundary Layer Theory}

A rough estimate of the time scales over which convection in magma chambers

as described above is efficient can be obtained by evaluating the overturn time predicted by boundary layer theory (e.g., Acheson, 1990).

The boundary layer theory postulates that the changes in composition that cause the unstable density profile are confined at the bottom of the shallow chamber, until the gravitational instability grows disrupting the system and causing overturn of less dense layers. The criterion for the onset of instability is that the Rayleigh number Ra be larger than $10^{3}$. The Rayleigh number is a non-dimensional quantity indicating the ratio of buoyancy and viscosity forces multiplied by the ratio of momentum and chemical diffusivities. For the setup 
used in our simulations, the Rayleigh number can be defined as

$$
\mathrm{Ra}=\frac{g \Delta \rho L^{3}}{\mu \kappa},
$$

where $g$ is gravity acceleration, $\Delta \rho$ is the density difference at the interface among the two magmas, $L$ is the vertical length scale of the reservoir, $\mu$ is viscosity and $\kappa$ is chemical diffusion coefficient.

A local Rayleigh number can be defined, in which the length scale is that of the boundary layer $\delta$, over which most of the compositional change occurs:

$$
\operatorname{Ra}_{\delta}=\frac{g \Delta \rho \delta^{3}}{\mu \kappa} .
$$

The boundary layer thinckness increases in time due to chemical diffusion:

$$
\delta=\sqrt{\kappa t},
$$

thus the local Rayleigh number increases in time as well. Convective overturn is predicted as the critical Rayleigh number $\operatorname{Ra}_{\delta}^{\mathrm{C}} \sim 10^{3}$ is reached, thus at a time $t_{\mathrm{O}}$ given by

$$
t_{\mathrm{O}} \sim\left(\operatorname{Ra}_{\delta}^{\mathrm{C}}\right)^{2 / 3} \frac{\mu^{2 / 3}}{g^{2 / 3} \Delta \rho^{2 / 3} \kappa^{1 / 3}} .
$$

Substituting the appropriate quantities for our simulations, $\mu \sim 500 \mathrm{Pas}$, $\Delta \rho \sim 100 \mathrm{~kg} / \mathrm{m}^{3}$ and $\kappa \sim 10^{-5} \mathrm{~m}^{2} \mathrm{~s}^{-1}$, yields an overturn time of the order of $1 \mathrm{~h}$.

This first-order estimate is of the same order of magnitude of the time scales obtained by the exponential fits above; nonetheless, the decaying trend of mixing efficiency cannot be incorporated in this theoretical framework. This same theory also confirms that longer homogenization times are related to lower initial density contrasts, as expected for buoyancy-only driven dynamics.

\section{References}

Acheson, D. J. (1990). Elementary Fluid Dynamics (Oxford: Clarendon Press)

Amoruso, A., Crescentini, L., and Sabbetta, I. (2014). Paired deformation sources of the Campi Flegrei caldera (Italy) required by recent (1980-2010) deformation history. J. Geophys. Res. Solid Earth 119, 858-879. doi:10.1002/ 2013JB010392 
Arienzo, I., Civetta, L., Heumann, A., Wörner, G., and Orsi, G. (2009). Isotopic evidence for open system processes within the Campanian Ignimbrite (Campi Flegrei - Italy) magma chamber. B. Volcanol. 71, 285-300. doi:10.1007/ s00445-008-0223-0

Arienzo, I., Moretti, R., Civetta, L., Orsi, G., and Papale, P. (2010). The feeding system of Agnano-Monte Spina eruption (Campi Flegrei, Italy): dragging the past into present activity and future scenarios. Chem. Geol. 270, 135-147. doi: 10.1016/j.chemgeo.2009.11.012

Bachmann, O. and Bergantz, G. W. (2006). Gas percolation in upper-crustal silicic crystal mushes as a mechanism for upward heat advection and rejuvenation of near-solidus magma bodies. J. Volcanol. Geoth. Res. 149, 85-102. doi:10.1016/j.jvolgeores.2005.06.002

Bagagli, M., Montagna, C., Papale, P., and Longo, A. (2017). Signature of magmatic processes in strainmeter records at Campi Flegrei (Italy). Geophys. Res. Lett. 44, 718-725. doi:10.1002/2016GL071875

Bain, A. A., Jellinek, A. M., and Wiebe, R. A. (2013). Quantitative field constraints on the dynamics of silicic magma chamber rejuvenation and overturn. Contrib. Mineral. Petr. doi:10.1007/s00410-013-0858-5

Chalot, F. and Hughes, T. (1994). A consistent equilibrium chemistry algorithm for hypersonic flows. Comput. Methods Appl. Mech. Engrg. 112, 25-40. doi: 10.1016/0045-7825(94)90017-5

Chiodini, G., Vandemeulebrouck, J., Caliro, S., D'Auria, L., De Martino, P., Mangiacapra, A., et al. (2015). Evidence of thermal-driven processes triggering the 20052014 unrest at Campi Flegrei caldera. Earth Planet. Sc. Lett. 414, 58-67. doi:10.1016/j.epsl.2015.01.012

Chouet, B. A. (1986). Dynamics of a fluiddriven crack in three dimensions by the finite difference method. J. Geophys. Res. 91, 13967 - 13992

Costa, A. and Macedonio, G. (2002). Nonlinear phenomena in fluids with temperature-dependent viscosity: An hysteresis model for magma flow in conduits. Geophys. Res. Lett. 29, 40-1-40-4. doi:10.1029/2001GL014493

De Siena, L., Del Pezzo, E., and Bianco, F. (2010). Seismic attenuation imaging of Campi Flegrei: Evidence of gas reservoirs, hydrothermal basins, and feeding systems. J. Geophys. Res. 115, 1-18. doi:10.1029/2009JB006938 
Degruyter, W. and Huber, C. (2014). A model for eruption frequency of upper crustal silicic magma chambers. Earth Planet. Sci. Lett. 403, 117-130. doi: 10.1016/j.epsl.2014.06.047

Di Renzo, V., Arienzo, I., Civetta, L., D’Antonio, M., Tonarini, S., Di Vito, M. A., et al. (2011). The magmatic feeding system of the Campi Flegrei caldera: Architecture and temporal evolution. Chem. Geol. 281, 227-241. doi:10.1016/j.chemgeo.2010.12.010

Di Vito, M., Isaia, R., Orsi, G., Southon, J., De Vita, S., d'Antonio, M., et al. (1999). Volcanism and deformation since 12,000 years at the Campi Flegrei caldera (Italy). J. Volcanol. Geoth. Res. 91, 221-246. doi:10.1016/ S0377-0273(99)00037-2

Di Vito, M. A., Acocella, V., Aiello, G., Barra, D., Battaglia, M., Carandente, A., et al. (2016). Magma transfer at Campi Flegrei caldera (Italy) before the 1538 AD eruption. Sci. Rep. 6, 32245. doi:10.1038/srep32245

D’Oriano, C., Poggianti, E., Bertagnini, A., Cioni, R., Landi, P., Polacci, M., et al. (2005). Changes in eruptive style during the AD 1538 Monte Nuovo eruption (Phlegraean Fields, Italy): the role of syn-eruptive crystallization. B. Volcanol. 67, 601-621. doi:10.1007/s00445-004-0397-z

Druitt, T. H., Costa, F., Deloule, E., Dungan, M., and Scaillet, B. (2012). Decadal to monthly timescales of magma transfer and reservoir growth at a caldera volcano. Nature 482, 77-80. doi:10.1038/nature10706

Garg, D., Longo, A., and Papale, P. (2018). Computation of compressible and incompressible flows with a spacetime stabilized finite element method. Comput. Math. with Appl. doi:10.1016/j.camwa.2018.03.028

Giordano, D., Russell, J., and Dingwell, D. (2008). Viscosity of magmatic liquids: A model. Earth Planet. Sc. Lett. 271, 123-134

Giudicepietro, F., Macedonio, G., and Martini, M. (2017). A Physical Model of Sill Expansion to Explain the Dynamics of Unrest at Calderas with Application to Campi Flegrei. Frontiers in Earth Science 5, 1-11. doi: $10.3389 /$ feart.2017.00054

Hauke, G. and Hughes, T. J. R. (1998). A comparative study of different sets of variables for solving compressible and incompressible flows. Comput. Methods Appl. Mech. Engrg. 153, 1-44. doi:10.1016/S0045-7825(97)00043-1 
Ishii, M. and Zuber, N. (1979). Drag coefficient and relative velocity in bubbly, droplet or particulate flows. AiChE J. 25, 843-855

Judenherc, S. and Zollo, A. (2004). The Bay of Naples (southern Italy): Constraints on the volcanic structures inferred from a dense seismic survey. $J$. Geophys. Res. 109, B10312. doi:10.1029/2003JB002876

Krumbholz, M., Hieronymus, C. F., Burchardt, S., Troll, V. R., Tanner, D. C., and Friese, N. (2014). Weibull-distributed dyke thickness reflects probabilistic character of host-rock strength. Nature communications 5, 3272. doi:10.1038/ ncomms 4272

Lange, R. (1994). The effect of $\mathrm{H}_{2} \mathrm{O}, \mathrm{CO}_{2}$ and $\mathrm{F}$ on the density and viscosity of silicate melts. Rev. Mineral. 30, 331-369

Liu, W. and Haller, G. (2004). Strange eigenmodes and decay of variance in the mixing of diffusive tracers. Phys. D Nonlinear Phenom. 188, 1-39. doi: 10.1016/S0167-2789(03)00287-2

Longo, A., Barsanti, M., Cassioli, A., and Papale, P. (2012a). A finite element Galerkin/least-squares method for computation of multicomponent compressible-incompressible flows. Comput. Geosci. 67, 57-71. doi:10.1016/j. compfluid.2012.07.008

Longo, A., Papale, P., Vassalli, M., Saccorotti, G., Montagna, C., Cassioli, A., et al. (2012b). Magma convection and mixing dynamics as a source of UltraLong-Period oscillations. B. Volcanol. doi:10.1007/s00445-011-0570-0

Longo, A., Vassalli, M., Papale, P., and Barsanti, M. (2006). Numerical simulation of convection and mixing in magma chamber replenished with $\mathrm{CO}_{2}$-rich magma. Geophys. Res. Lett. 33. doi:10.1029/2006GL027760

Mangiacapra, A., Moretti, R., Rutherford, M., Civetta, L., Orsi, G., and Papale, P. (2008). The deep magmatic system of the Campi Flegrei caldera (Italy). Geophys. Res. Lett. 35, L21304. doi:10.1029/2008GL035550

Marchetti, E., Ichihara, M., and Ripepe, M. (2004). Propagation of acoustic waves in a viscoelastic two-phase system: influence of gas bubble concentration. J. Volcanol. Geoth. Res. 137, 93-108. doi:10.1016/j.jvolgeores.2004.05. 002 
Montagna, C., Papale, P., and Longo, A. (2015). Timescales of mingling in shallow magmatic reservoirs. Geological Society, London, Special Publications 422, SP422-6. doi:10.1016/j.chemgeo.2009.11.012

Morgavi, D., Perugini, D., De Campos, C., Ertel-Ingrisch, W., and Dingwell, D. (2013). Time evolution of chemical exchanges during mixing of rhyolitic and basaltic melts. Contrib. Mineral. Petr. 166, 615-638. doi: 10.1007/s00410-013-0894-1

Papale, P., Montagna, C. P., and Longo, A. (2017). Pressure evolution in shallow magma chambers upon buoyancy-driven replenishment. Geochem. Geophy. Geosy. 18. doi:10.1002/2016GC006731

Papale, P., Moretti, R., and Barbato, D. (2006). The compositional dependence of the saturation surface of $\mathrm{H}_{2} \mathrm{O}+\mathrm{CO}_{2}$ fluids in silicate melts. Chem. Geol. 229, 78-95. doi:10.1016/j.chemgeo.2006.01.013

Parmigiani, A., Huber, C., and Bachmann, O. (2014). Mush microphysics and the reactivation of crystal-rich magma reservoirs. J. Geophys. Res. Solid Earth 119, 6308-6322. doi:10.1002/2014JB011124

Perugini, D., De Campos, C. P., Petrelli, M., and Dingwell, D. B. (2015). Concentration variance decay during magma mixing: A volcanic chronometer. Sci. Rep. 5, 1-10. doi:10.1038/srep14225

Perugini, D. and Poli, G. (2012). The mixing of magmas in plutonic and volcanic environments: Analogies and differences. Lithos 153, 261-277. doi:10.1016/j. lithos.2012.02.002

Pistone, M., Blundy, J., and Brooker, R. A. (2017). Water transfer during magma mixing events: Insights into crystal mush rejuvenation and melt extraction processes. Am. Mineral. 102, 766-776. doi:10.2138/am-2017-5793

Reid, R. C., Prausnitz, J., and Sherwood, T. (1977). The properties of gases and liquids. International Series in the Physical and Chemical Engineering Sciences (New York: McGraw Hill)

Schleicher, J. M., Bergantz, G. W., Breidenthal, R. E., and Burgisser, A. (2016). Time scales of crystal mixing in magma mushes. Geophys. Res. Lett. , 15431550doi:10.1002/2015GL067372 
Shakib, F., Hughes, T. J., and Johan, Z. (1991). A new finite element formulation for computational fluid dynamics: X. The compressible Euler and Navier-Stokes equations. Comput. Methods Appl. Mech. Engrg. 89, 141-219. doi:10.1016/0045-7825(91)90041-4

Sparks, R. S. J. (2003). Forecasting volcanic eruptions. Earth Planet. Sci. Lett. 210, 1-15. doi:10.1016/S0012-821X(03)00124-9

Tonarini, S., D'Antonio, M., Di Vito, M. A., Orsi, G., and Carandente, A. (2009). Geochemical and BSrNd isotopic evidence for mingling and mixing processes in the magmatic system that fed the Astroni volcano (4.13.8 ka) within the Campi Flegrei caldera (southern Italy). Lithos 107, 135-151. doi: 10.1016/j.lithos.2008.09.012

Turner, J. S. and Campbell, I. H. (1986). Convection and mixing in magma chambers. Earth-Science Reviews 23, 255-352. doi:10.1016/0012-8252(86) 90015-2

Wark, D., Hildreth, W., Spear, F., Cherniak, D., and Watson, E. (2007). Preeruption recharge of the Bishop magma system. Geology 35, 235. doi:10.1130/ G23316A.1

Zollo, A., Maercklin, N., Vassallo, M., Dello Iacono, D., Virieux, J., and Gasparini, P. (2008). Seismic reflections reveal a massive melt layer feeding Campi Flegrei caldera. Geophys. Res. Lett. 35, L12306. doi:10.1029/2008GL034242 


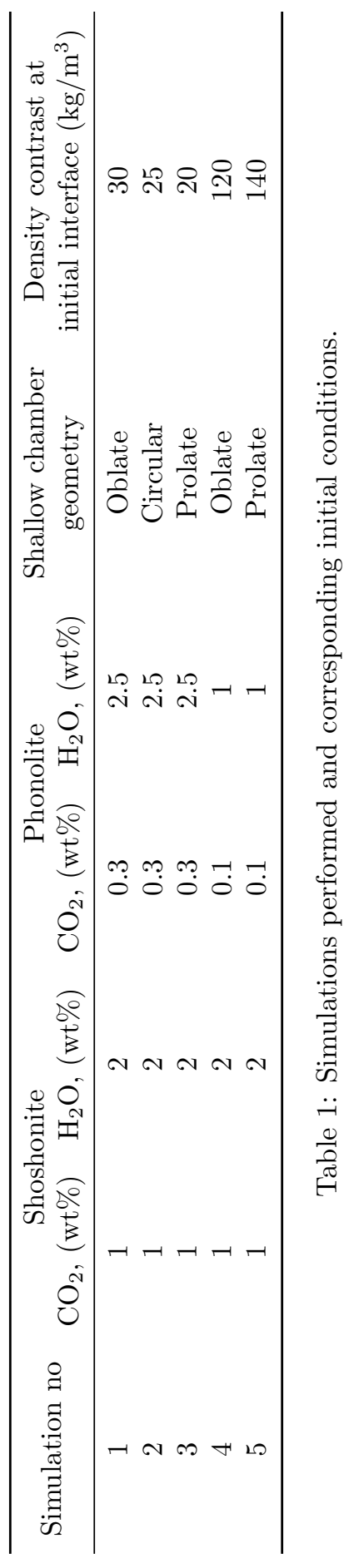




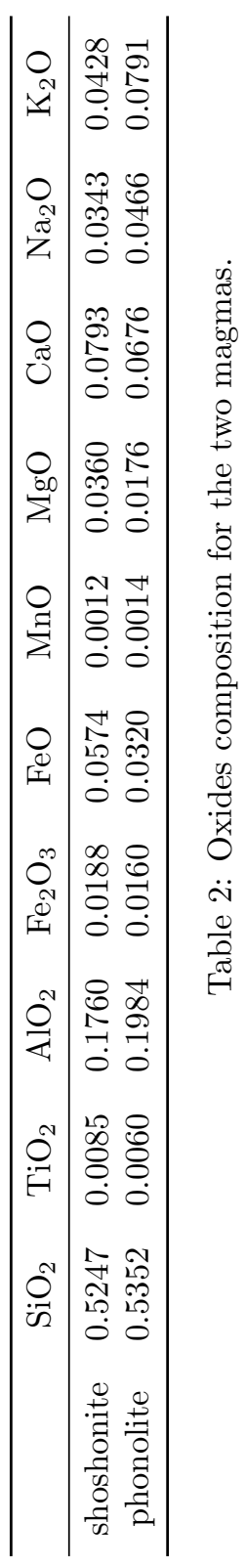



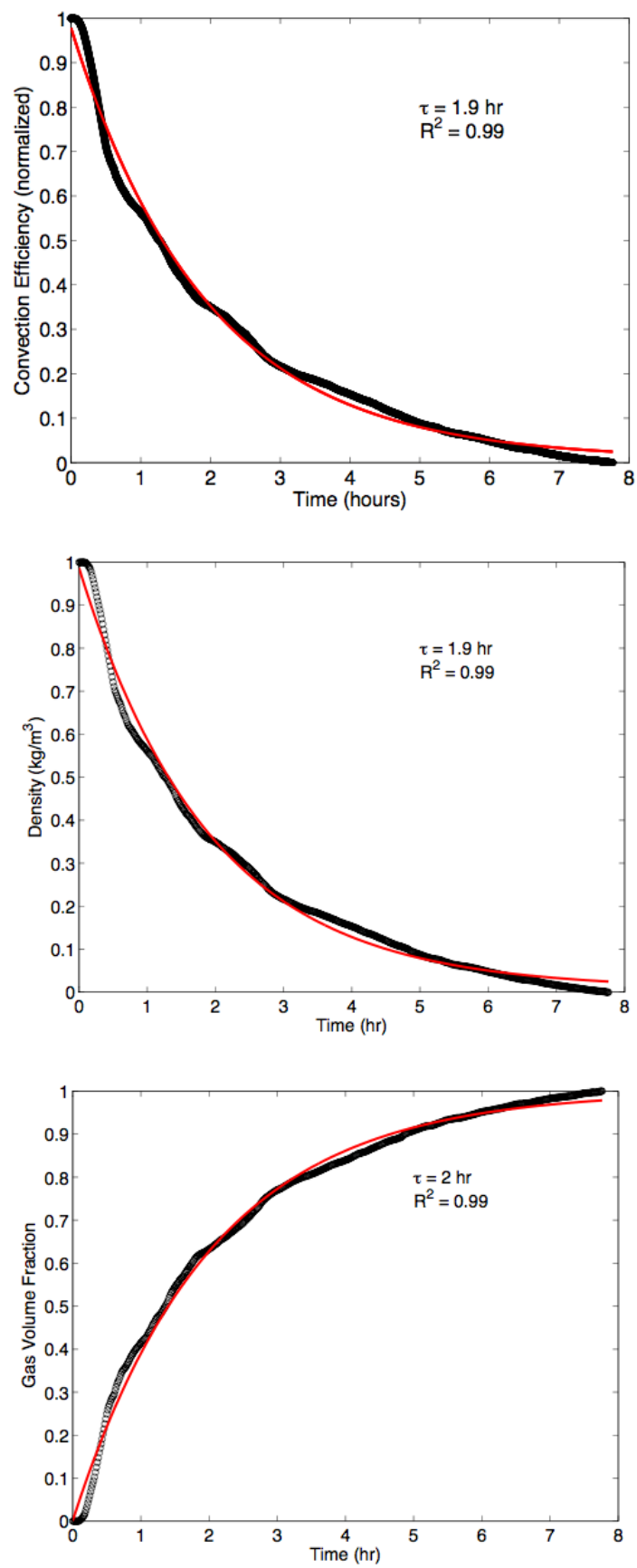

Figure 5: Exponential fits for a) convection efficiency, b) density and c) gas volume fraction for simulation 1 . 


\begin{tabular}{cc}
\hline Simulation & Time constant, hours \\
\hline 1 & 2.0 \\
2 & 2.6 \\
3 & 13 \\
4 & 2.2 \\
5 & 2.4 \\
\hline
\end{tabular}

Table 3: Exponential decay times for the five simulated setups. 

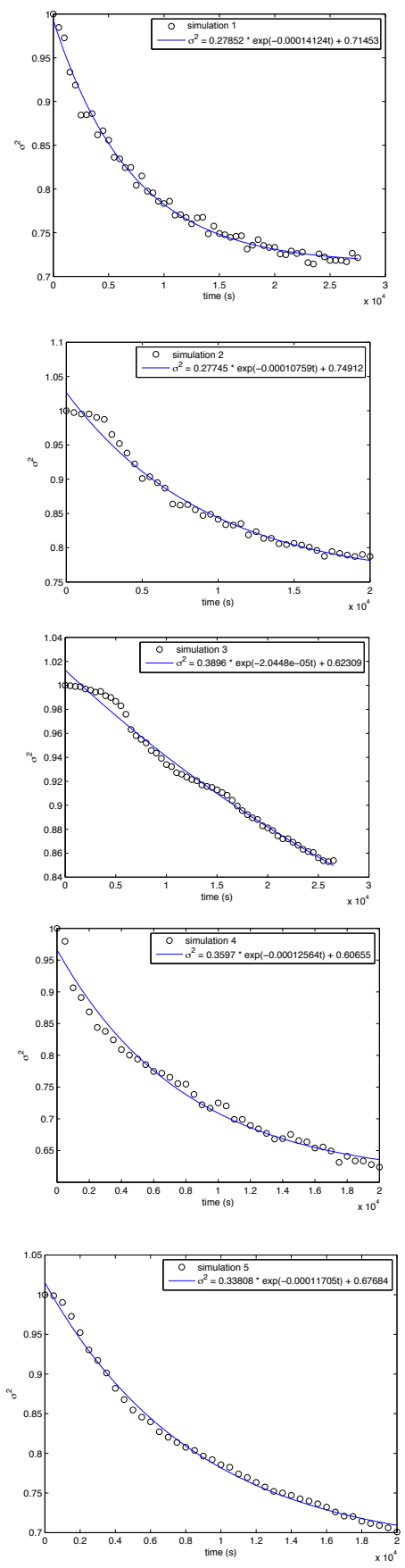

Figure 6: Concentration variance decay with time for the five simulated setups, alongside exponential fits. 


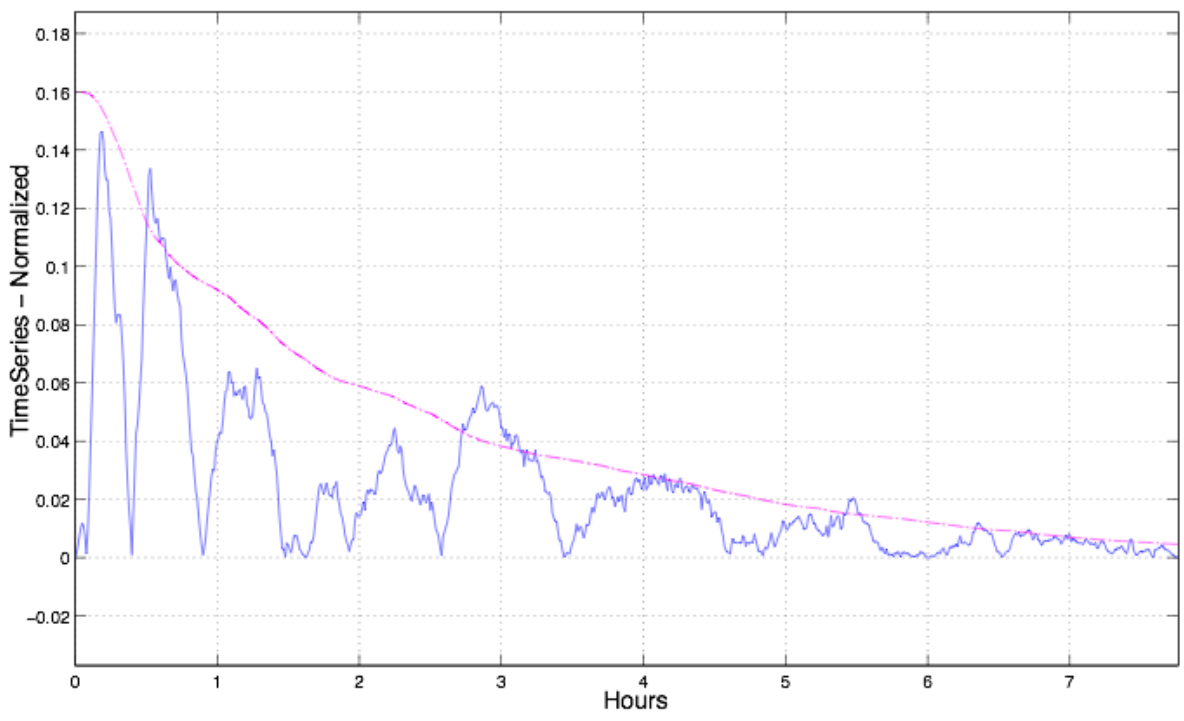

Figure 7: For simulation 1, amplitude of ground deformation at a synthetic station atop the magmatic system, in blue; superimposed is the convection efficiency, in violet. 


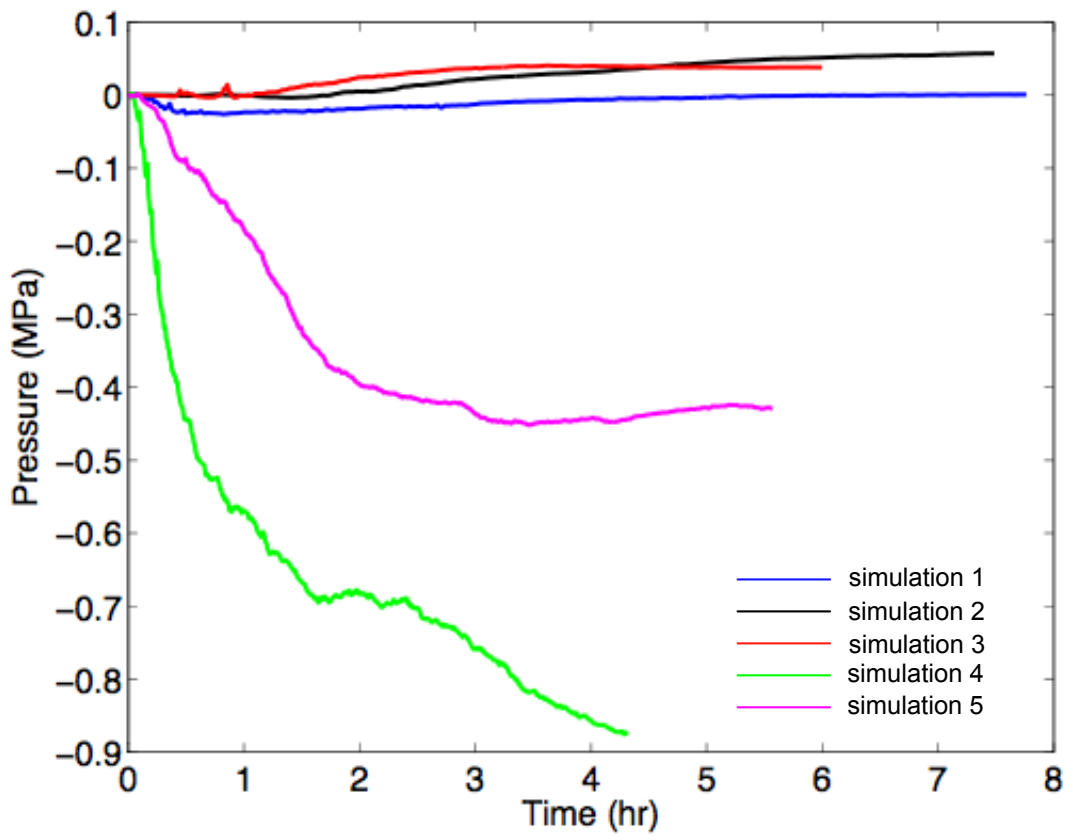

Figure 8: Pressure evolution at the top of the magmatic system for the 5 simulated scenarios. 